This report was prepared LE A L NOTICE

Stales, nor the Commission, nor any persor acting on behalf of thed work. Netther the United racy, completeness, or wanty or representation, expressed or if of the Commission:

rack. completeness, of usefulness of the informatessed ar implied, with respect to the ace privately ownent, apparatus, method, or process disclosed in this report, or that the use

B. Assumes uny liar

of any information, apparatus, method, or process of, or for damagee resulting from the

As used in the above, "person actlag on behalf of the com in this report.

ployee or contractor of the Commission on bebalf of the Commsesion" includes an

such employee or contractor of the Cominissiton of of such vontractor, to the extent the

with the Cos, or providea access to, any tnformation puplose of euch contractor prepareo,

mployment with such contractort to hts employment or contract

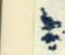

\title{
A STEANDARSSS AND CALIBRATION \\ PROGRAM IN A LARGE \\ DEFENSE PLANT
}

\author{
by \\ J. F. Hadley, Supervisor \\ Primary Standards Laboratory \\ Bendix Corporation \\ Kansas City Division
}

Presented to IEEE Symposium on Measurements and Instrumentation at the ContinentaI Hotel in Kansas City, Missouri on November 21, 1963

November 1963 


\section{DISCLAIMER}

This report was prepared as an account of work sponsored by an agency of the United States Government. Neither the United States Government nor any agency Thereof, nor any of their employees, makes any warranty, express or implied, or assumes any legal liability or responsibility for the accuracy, completeness, or usefulness of any information, apparatus, product, or process disclosed, or represents that its use would not infringe privately owned rights. Reference herein to any specific commercial product, process, or service by trade name, trademark, manufacturer, or otherwise does not necessarily constitute or imply its endorsement, recommendation, or favoring by the United States Government or any agency thereof. The views and opinions of authors expressed herein do not necessarily state or reflect those of the United States Government or any agency thereof. 


\section{DISCLAIMER}

Portions of this document may be illegible in electronic image products. Images are produced from the best available original document. 


\title{
A STANDARDS AND CALIBRATION PROGR AM \\ IN A LARGE DEFENSE PLANT
}

\begin{abstract}
The quality and reliability needed in today's weapon systems can be assured only by a system of repeatable and accurate measurements. Such a system must extend from the nation's legal standards of measurement at the National Bureau of Standards to the many thousands of measuring instruments used by defense contractors in the design, production and testing of weapons, weapons components, and materials.

This paper describes the standards and calibration system in operation at the Kansas City Division of the Bendix Corporation, It shows its relationship to the Atomic Energy Commission's Standards and Calibration System and to the National Bureau of Standards. The Bendix Primary Standards Laboratory maintains reference standards for all electrical, environmental and dimensional measurements made throughout the plant. This laboratory coordinates a standards and calibration programutilizing five calibration departments, to provide for the periodic calibration of all plant measuring instruments - and all acceptance equipment in vendor's plants. Technical audits and visual inspections of calibration activities assure the adequacy of the calibration work performed.
\end{abstract}

Introduction:

Much of industry today is faced with the task of manufacturing and testing products that meet performance specifications rarely heard of a few years ago. This is particularly true in that portion of industry devoted to fulfilling the nations military and space needs. Compliance with specifications can be assured only by reliable inspection and testing of products. Since a reliable inspection and testing program is dependent upon the ability to make accurate measurements, many companies have established standards and calibration programs tailored to their own particular measurement needs.

The Kansas City Division of Bendix is one of several Atomic Energy Commission prime contractors located throughout the country. The plant, which employs approximately 7500 people, is engaged in the production of non-nuclear components and systems for atomic weapons. More than 80,000 measuring instruments, gages, and testers are used throughout the plant during the development, manufacturing and testing of products. These devices range from intricate mechanical parts, with tolerances measured in millionths of an inch, to complex radar assemblies with specifications pushing the state of the art in microwave measurements.

To meet the exacting specifications required by the AEC in producing and testing a quality product, a plant wide standards and calibration program was established at Bendix approximately six years ago. Actually, calibration activities had been in existence prior to that time, but 1957 marked the start of a coordinated program affecting all measuring instruments and measurement standards at Bendix. 


\section{Organization:}

The responsibility for the administration of this standards and calibration program has been assigned to the Bendix Primary Standards Laboratory. It is a part of the Bendix Test Laboratory, a Quality Division organization which provides testing and calibration services to all plant departments. The major functions of the Primary Standards Laboratory are:

1. Maintain basic measurement standards for all electrical and physical measurements made at Bendix

2. Assign responsibility for the calibration of each measuring instrument used in the plant, to one of the five Bendix calibrating departments

3. Calibrate all measurement standards used by the five calibrating departments

4. Perform periodic surveys of the calibrating departments, to assure the continued adequacy of their calibration activities

5. Perform special measurements requiring highly accurate measuring equipment not available elsewhere in the plant.

Stated briefly, the purpose of our standards and calibration program is to assure ourselves and our customer that measurements relating to our products are made with instrumentation which is repeatable and accurate. Since components and assemblies produced and tested in our plant must be compatible with those produced by other AEC contractors, it is imperative that all such measurements be related to a common system of standards.

The AEC recognized this fact early in its history and established an AEC Primary Standards Laboratory for the purpose of providing a systemwide reference for all measurements made. This laboratory is operated for the AEC by the Sandia Corporation Physical and Electrical Standards Department at Albuquerque, New Mexico.

Figure 1 shows the relationship of the organizations involved in our standards and calibration program. At the top of the chain of standards is the National Bureau of Standards located at Washington D. C. and Boulder, Colorado. NBS of course maintains the nation's legal standards of measurement.

The AEC Primary Standards Laboratory at Sandia is responsible for maintaining the reference standards for measurements made throughout the AEC complex. Standards are periodically rotated between this laboratory and NBS, to establish measurement capabilities as accurate as required to meet the needs of AEC contractors. The AEC Primary Standards Laboratory is also responsible for reporting on the performance of the AEC contractors' calibration laboratories. 


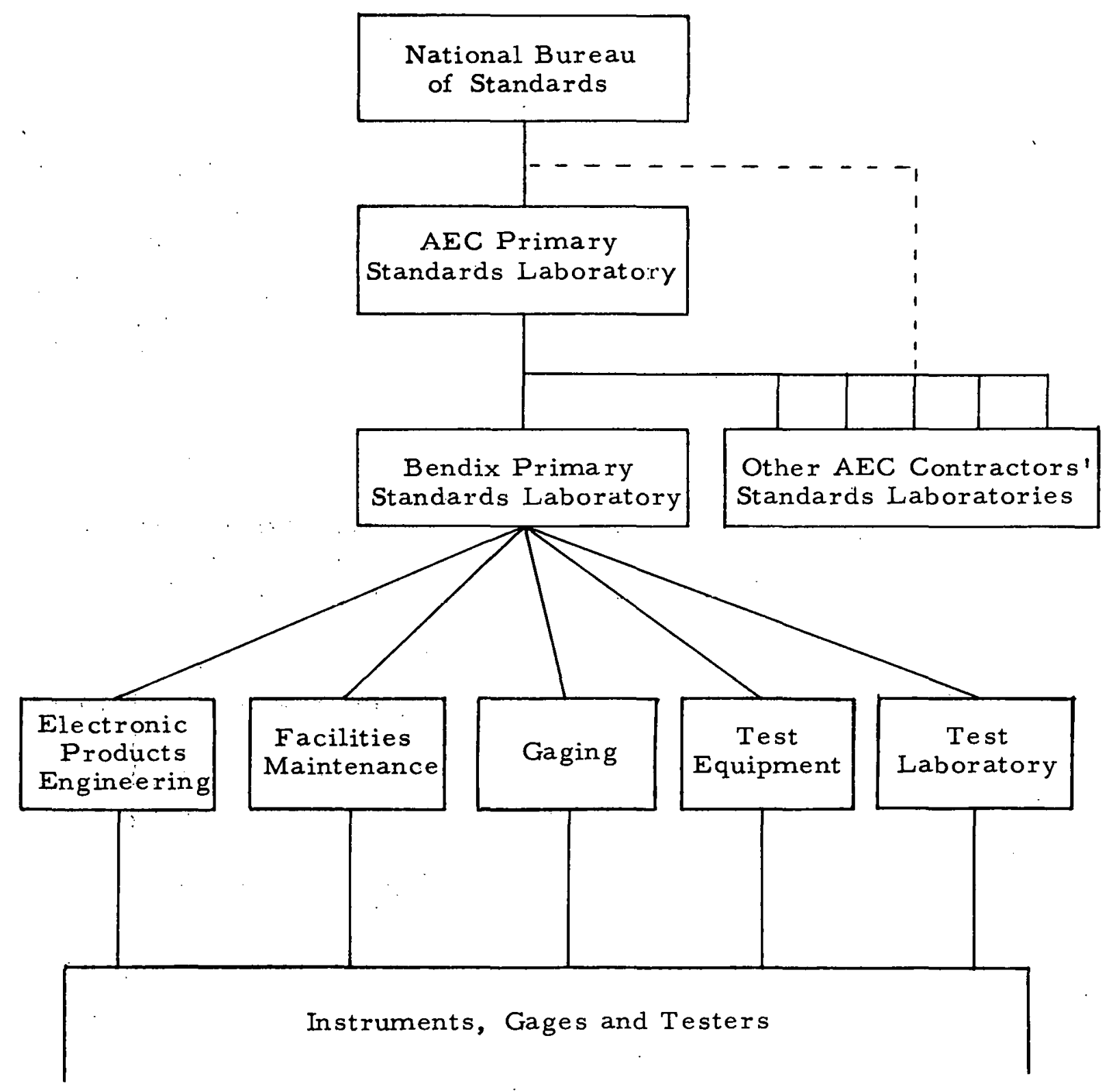

Figure 1. Calibration Traceability Chart 
The Primary Standards Laboratory at Bendix periodically sends its reference standards to Sandia for calibration, as do each of the other AEC prime contractors. If the measurement capability required by a contractor is not available from Sandia, a contractor may send a needed standard directly to NBS for calibration, as indicated by the dash line in Figure 1. For example, proving rings and load cells used for force measurements from 1000 to 600,000 pounds are sent by Bendix directly to NBS for calibration. Saturated standard cells were calibrated by NBS in 1960, and have since been periodically intercompared with the Sandia bank of saturated cells. The calibration system is flexible enough to allow one or more calibration steps to be omitted if necessary to provide the accuracy required at the measuring instrument level.

The calibration of each measuring instrument at Bendix is performed by one ơ five calibration departments - Electronic Products Engineering, Facilities Maintenance, Gaging, Test Equipment, and the Test Laboratory. Each of these departments maintains its own set of standards, as needed to fulfill its particular calibration requirements. All such standards are calibrated by the Bendix Primary Standards Laboratory at periodic calibration intervals. Organizationally, the se departments are independent of the Primary Standards Laboratory, but they are responsible to the Primary Standards Laboratory for the adequacy of their calibration activities. Approximately 180 persons are engaged in the standards and calibration activities at Bendix.

The Electronic Products Engineering Department calibrates the electrical measuring instruments used by the Engineering Division in its product design, development and testing programs.

The Facilities Maintenance Department is responsible for electrical and environmental instrument calibration on production process control equipment and on plant utilities.

N1l dimensional, weight, torque and force measuring instruments are calibrated by the Gaging Department.

The Test Equipment Department calibrates all electrical and cnvironmental medsuring instruments used by the Quality Division for product inspection and acceptance.

The Test Laboratory calibrates laboratory measuring instruments which are used to perform special laboratory tests relating to characteristics of products, materials or processes. Actually, this calibration service is performed by the Primary Standards Laboratory, acting as a measuring instrument calibration group in addition to its responsibilities for the calibration of standards.

Figure 2 shows the principal areas of measurement in which the calibration departments have measurement capabilities. In cases where the number of measuring instruments for a particular type measurement is small, or the calibration equipment required $m$ akes it uneconomical to duplicate facilities, the Primary Standards Laboratory may ralihra.te the 
instruments directly. If the volume of work increases, the calibration responsibility may be transferred to one of the calibrating departments.

\section{Calibration Control:}

Before describing our calibration control system, let us define some of the terms used frequently in this paper.

Measuring Instrument - Any general or special purpose device, gage, tool or tester which is used to measure a characteristic of the product or product environment during design, development, production, inspection or acceptance.

Standard - A device which establishes a unit of measurement and which is used for the calibration of another standard or a measuring instrument.

Calibration - The process by which a standard or a measuring instrument is compared with a standard having a higher precision and accuracy.

The calibration control system used at Bendix is planned to assure that all measuring instruments and standards are calibrated at regularly established intervals of time or usage. Each measuring instrument is assigned for calibration purposes to one of the five calibrating departments previously mentioned. Since the division of responsibility between these departments is clearly defined, most calibration assignments are self evident and only occasionally is it necessary for the Primary Siandards Laboratory to determine to which department an instrument should be assigned.

When a new instrument is received, it is routed directly to the responsible calibrating department. The calibrating department performs the necessary calibration, determines the calibration interval and prepares a calibration record card. Before an instrument is placed in service a "Notice of Calibration" label is attached to it, showing the date calibrated, the calibration expiration date and the department performing the calibration. In some cases, calibration accuracy or applicable drawing number and issue is included on the calibration label. If a gage is too small to receive a calibration label, colored dots are used to indicate the week that recalibration is due.

The calibration record card serves as a permanent record of the calibration history of the instrument and is used to initiate recall of the instrument prior to the calibration expiration date. In case an instrument can not be callbrated prior to its expiration date, a red-bordered "Calibration Overdue" label is attached to the instrument. An orange-bordered "Out of Service" label is also used to indicate an instrument which is temporarily out of service. Figure 3 shows the calibration labels used.

In some cases, gages or other instruments are calibrated on a usage basis rather than time interval. Such instruments are checked out from the calibrating department and must be returned at the end of each day's use. They are then recalibrated before being re-is sued. 


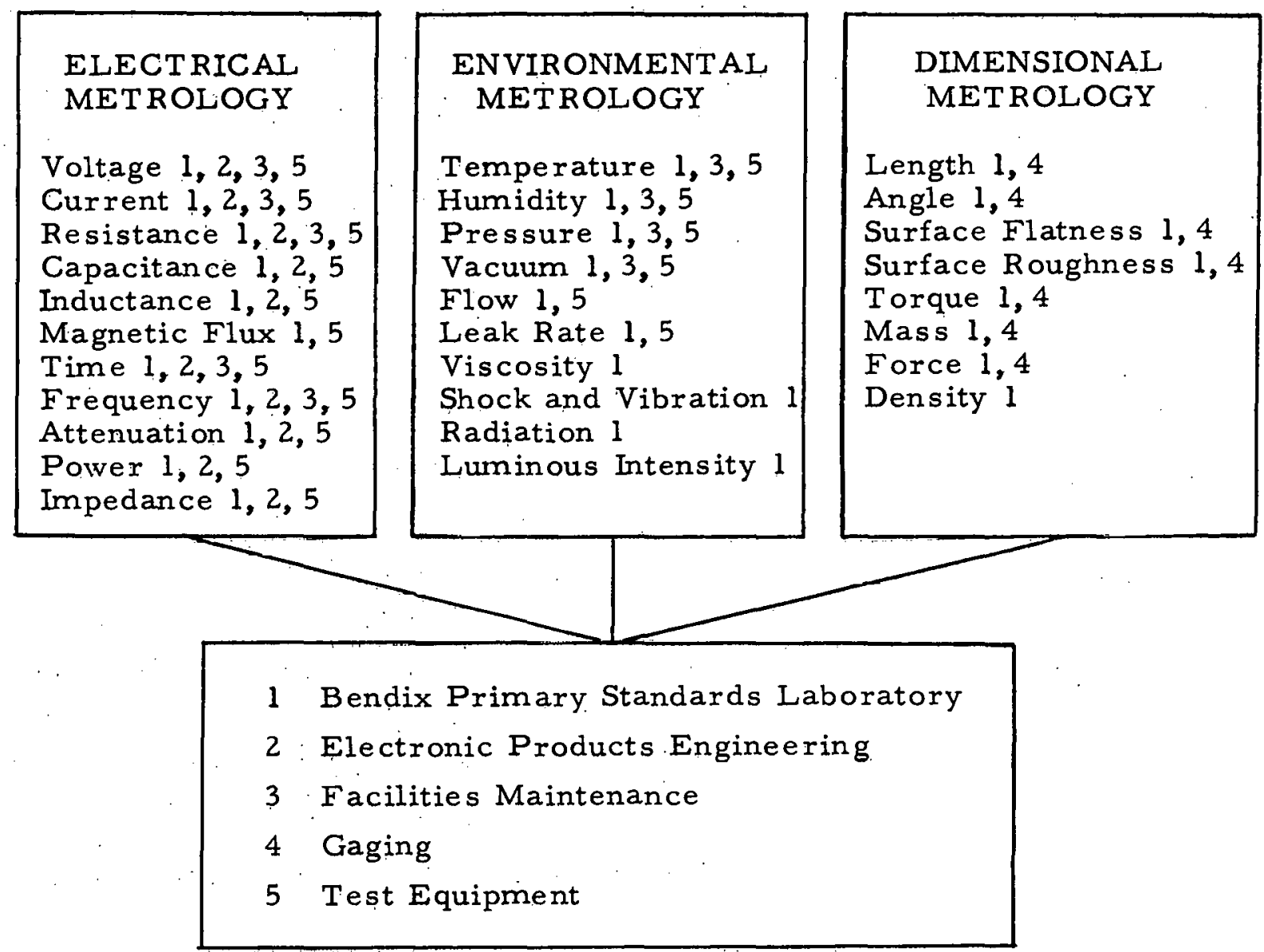

Figure 2. Principal Areas of Measurement Capability 
The control system used is mandatory, and all departments using measuring instruments must see that uncalibrated or expired instruments are not used for product-related measurements.

In the Gaging Department and the Primary Standards Laboratory, an Electronic Data Processing system is used to control calibration intervals and provide notices to the calibrating departments each time an instrument is due for calibration. This system significantly reduces clerical time when a large number of instruments must be scheduled for calibration. It is planned to modify this system to provide more information and extend it to all calibrating departments within the next year.

Calibration Interval Evaluation:

The establishment of optimum calibration intervals is one of the most important factors in the operation of a calibration activity. Ideally, the interval selected should be such that the instrument is calibrated as soon as it exceeds its required tole rance, and not before. Shorter intervals are inefficient, both because they create unnecessary calibration work load and because they incrcase the uut-of-service time on good instruments. Longer intervals may result in a decrease in the reliability of measurements made. It is usually necessary to recalibrate an instrument to determine whether it is within tolerance.

Each calibration department establishes calibration intervals on the basis of judgement and experience with similar instruments. Ordinarily all instruments of a particular type are assigned the same calibration interval, but conditions of use or the accuracy needed for a particular application may create exceptions. Calibration intervals vary from once a day to once a year on measuring instruments and from once a month to once every five years on standards. The average interval is approximately one month on measuring instruments and six months on standards. Each calibration department reviews instrument calibration data periodically, to determine when intervals should be lengthened or shortened.

Faced with an increasing work load at the end of 1960, the Primary Standards Laboratory reviewed calibration data on all of the standards and measuring instruments which were then on a Primary Standards Laboratory calibration schedule. Out of a total of 1258 instruments reviewed - the calibration interval was doubled on 793 , left the same on 423 , and shortened on 42 . This resulted in a 23 percent reduction in yearly calibration time required.

Near the end of 1961, the 1961 calibration data on these same instruments was reviewed, to determine the effect of the reduction in calibration. A total of 17 percent of all calibrations made during 1961 showed instruments to be out of tole rance. It was significant that only 8 percent of the calibrations made un instruments having a lengthened interval were out of tolerance, compared to 18 percent of the calibrations on instruments remaining on the same interval - and 34 percent of the calibrations on instruments changed to a shorter interval. This data clearly indicated that the calibration interval changes ma de at the end of 1960 were justified. It also indicated the need to further shorten intervals on the group showing the 34 percent out of tolerance, or to replace them with more reliable in struments. 
Records of out-of-tolerance conditions have been kept since 1961 on a monthly basis, as a guide to the validity of the selected calibration intervals. Each time an instrument is recalibrated, a review is made to see if an interval change should be made. In 1962, as in 1961, 17 percent of all calibrations showed out-of-tolerance conditions. This has dropped to 14. 7 percent for the first ten months of 1963.

A 15 percent out-of-tolerance level at the time of calibration usually results in less than 7.5 percent of the instruments in use being out-oftolerance. This level is considered a reasonable compromise between reliability and economy.

So far, this analysis of out-of-tolerance conditions has been limited to the approximately 1800 standards and measuring instruments calibrated by the Primary Standards Laboratory. Modification and extension of our electronic data processing system to other calibrating departments will enable similar data to be used in the future to evaluate the effectiveress of selected calibration intervals on all of the 80,000 instruments in the plant.

Vendor Calibration:

The scope of the work at Bendix necessitates procurement of components from vendors located throughout the United States. Some of these components are inspected and accepted by Bendix personnel at the vendors' plants, utilizing gages and testers supplied by the Bendix calibration departments. Each of the measuring instruments used for source acceptance at the vendors' plants is subject to the same type of calibration control as exists in the plant. The appropriate calibration department (Test Equipment or Gaging) is responsible for this calibration, which may be accomplished as follows:

1. Equipment may be calibrated in the vendor's plant, by Gaging or Test Equipment perscnnel using standards calibrated by Bendix.

2. Equipment may be returned to Bendix for calibration.

3. Equipment may be calibrated by an independent calibration laboratory, under a contract approved by the Bendix Primary Standards Laboratory and by the AEC. In such cases, the calibration laboratory's standards are calibrated by Bendix.

4. Arrangements may be made with another AEC prime contractor to provide calibration service. This is done to avoid duplication, in cases where two or more AEC contractors accept product in in the same vendor's plant.

Both the Gaging and Test Equipment departments have calibration personnel stationed at four field offices, under the supervision of our Field Inspection Department. Most of the electrical and environmental field calibration is accomplished by these people, while most of the dimensional calibration is accomplished by two approved commercial laboratories. 
The Field Inspection Department has the responsibility for surveillance of all vendors supplying productive material to Bendix. Part of this responsibility is to assist the vendors in setting up and maintaining their own calibration programs for their in-process and inspection equipment. Technical advice is frequently given to vendors by Bendix Field Inspection and calibration department personnel. On occasion Field Inspection may require that a vendors' standards be calibrated by Bendix, when experience indicates that a correlation problem may exist or when tolerances are extremely critical.

Calibration Surveys:

1

As a means of as suring conformance to the requirements of our calibration program, the Primary Standards Laboratory conducts periodic surveys of each calibration department. These surveys cover such factors as:

1. Adequacy of the calibration intervals selected by the calibration departments

2. Adherence to the established calibration schedules, and suitability of the manner in which the state of calibration is indicated on the equipment

3. Acceptability of the calibration methods and associated records and procedures

4. The type of equipment calibrated and the adequacy of the standards and their environment.

After each calibration survey, a report is sent to the department head responsible for the calibration activity surveyed, recommending corrective action where necessary. Follow-up surveys are made to as sure that corrective action has been accomplished. These surveys have recently been expanded to include the field calibration activities and the independent laboratories having calibration cuntracts with Bendix.

Similar surveys of all Bendix calibration activities are made by the AEC Primary Standards Laboratory on an annuál basis.

Technical Audits:

Technical audits are conducted by both the Bendix Primary Standards Laboratory and the AEC Primary Standards Laboratory. Such audits usually consist of sending an "audit piece", containing an instrument or part of known value, to one or more calibration departments and asking the dcpartmcnt to inedsure or calibrate the audit piece to the best of its ability. Such items as gage blocks, barometers, thermometers, voltmeters, standard cells, resistors, and microwave attenuators have been used. The results of the measurements are then sent to the group performing the measurement. Such audits serve as an indication of the capabilities of the calibration group audited. 
The concept of technical audits has been extended to a formal program of periodic audits on some products manufactured by Bendix. In one case, a unit similar to the product tested is rotated periodically between the production testers, the Bendix Standards Laboratory and the AEC Primary Standards Laboratory. Special test equipment located in the two standards laboratories measures the same parameters that are checked on the production testers by the product inspector. The data generated is analyzed and used to evaluate the accuracy of the production tester measurements. Such a program is very useful in cases where the product specifications approach the accuracy obtainable in the standards laboratories.

\section{Conclusion:}

Advances in scientific knowledge and technology will doubtlessly demand greater precision and accuracy in future measurements. Metrologists must find ways of adapting today's standards laboratory measurement techniques to the needs of tomorrow's production inspection activities. The standards and calibration system described here has proved successful in meeting the present requirements of Bendix and the Atomic Energy Commission and is, we believe, adaptable to these future needs. 